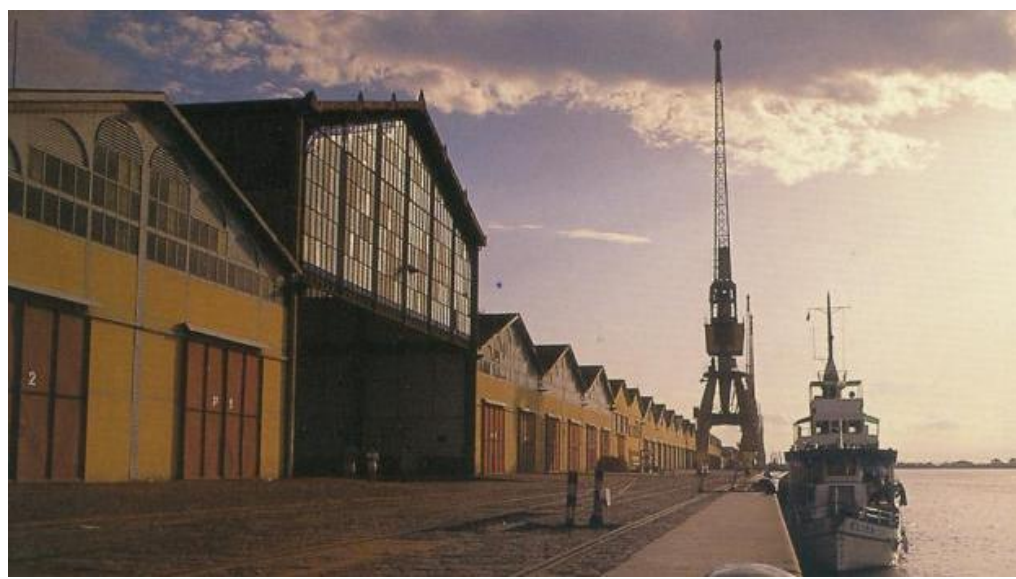

\title{
A ficcionalização dos espaços urbano e rural e a construção do ethos gaúcho na canção "Desgarrados"
}

The fictionalization of urban and rural spaces and the construction of ethos in the song "Desgarrados"

Elisane Regina Cayser ${ }^{1}$

Orcid ID: https://orcid.org/0000-0003-0802-3939

Luciana Maria Crestani ${ }^{2}$

Orcid ID: https://orcid.org/0000-0003-1265-7803

\section{Resumo:}

O objetivo deste artigo é analisar como se constrói a representação dos espaços urbano e rural na canção "Desgarrados", de Mário Barbará e Sérgio Napp, e depreender o ethos gaúcho atrelado a tal representação. Para tanto, utilizam-se preceitos da teoria semiótica discursiva e de estudos sobre ethos. Também contribuem as considerações de Pesavento $(1989,1993)$ sobre formação identitária e de Vecchi (2017) sobre a memória e a relação do sujeito com o passado. A análise aponta que as redes figurativas estabelecidas na canção e o ethos melancólico construído pelo enunciador evidenciam um desejo do gaúcho supostamente deslocado das suas origens de retomar um passado que, na realidade, jamais existiu da forma como é cantado, demonstrando, por isso, uma atração por um tempo e um lugar mais imaginados do que vividos.

Palavras-chave: Semiótica discursiva; Ethos; Cancioneiro gaúch;. Desgarrados.

\begin{abstract}
:
This study aims to analyze how the representation of urban and rural spaces is constructed in the song "Desgarrados", by Mário Barbará and Sérgio Napp, and understand the ethos of the gaúcho (population from the state of Rio Grande do Sul, Brazil) attached to such representation. Therefore, the precepts of both the discursive semiotic theory and the studies on ethos are used. The considerations by Pesavento $(1989,1993)$ on identity formation and by Vecchi (2017) on the memory and relationship of subjects with the past are also used. The analysis indicates that the figurative networks established in the song and the melancholic ethos constructed by the enunciator show a desire of the gaúcho, who is supposedly distanced from their origins, to regain a past that never actually existed in the way the song portrays. This shows an attraction for a time and place that have been imagined rather than lived.
\end{abstract}

Keywords: Discursive semiotics; Ethos; Gaúcho songbook; "Desgarrados".

\footnotetext{
${ }^{1}$ Professora do Curso de Letras da Universidade de Passo Fundo. Especialista em Linguística Aplicada à Alfabetização (PUCRS). Mestre em Letras (PUCRS). Doutoranda em Letras (UPF). E-mail: ecayser@upf.br.

${ }^{2}$ Doutora em Letras (UPM-SP), Mestre em Educação (UPF). Professora no Curso de Letras e no

Programa de Pós-Graduação em Letras da Universidade de Passo Fundo. E-mail: lucianacrestani@upf.br
} 


\section{Introdução}

O que se concebe como presente é constantemente construído a partir de fragmentos do passado, que se ressignificam a partir de novas experiências. Esses traços do passado são retomados através das memórias de uma determinada comunidade, memórias essas que são evidenciadas tanto no contexto de convívio cotidiano quanto na literatura, a qual preenche, de certa forma, alguns vazios deixados pela história oficial, ou, em outros casos, recria alguns episódios de acordo com os anseios de um grupo.

É nesse contexto que se inserem as canções que expressam, muitas vezes, o pensamento de um determinado grupo a respeito de si e do outro, indo, portanto, muito além da mera fruição no campo estético. Pode-se dizer, nesse sentido, que as canções demarcam a identidade de pessoas, grupos e povos, denotando aspectos religiosos, políticos, geográficos, econômicos, entre tantos outros.

Considerando essa ligação das canções com a cultura é que se busca, nesse artigo, verificar o ethos de gaúcho que se projeta na letra da canção "Desgarrados", composição de Mário Barbará e Sérgio Napp que relata o deslocamento de gaúchos do interior do estado do Rio Grande do Sul para a capital do estado - Porto Alegre -, especialmente ocorrido em meados dos anos de 1970. Pretende-se constatar de que forma, na canção, são abordadas as questões relativas à imagem coletiva construída acerca do gaúcho que outrora morava em ambientes rurais e que, em função do êxodo, migrou para contextos urbanos, buscando analisar as imagens construídas desses dois espaços.

Para tanto, são utilizados, na primeira secção, alguns conceitos sobre formação identitária, ao que se seguem considerações sobre a formação específica do gaúcho, na perspectiva de autores como Pesavento $(1989,1993)$. Na sequência, são feitas breves considerações sobre a semiótica discursiva e a enunciação no viés da semiótica, para o que são utilizados estudos de Fiorin (1997, 2003, 2017) e Barros (1997 e 2012)³ principalmente os ligados à formação do ethos, sendo também explorados os preceitos de Maingueneau (2008). Além disso, são tomadas como referências constantes ao longo do trabalho as contribuições de Vecchi (2017) relativas aos estudos sobre a memória e a

\footnotetext{
${ }^{3}$ Luiz Tatit desenvolve estudos relacionados à canção, enfocando aspectos como ritmo da melodia, harmonia, relação entre melodia e letra, vertente que passou a ser denominada Semiótica da Canção. Os trabalhos de Tatit apontam a contribuição do arranjo e da harmonia, da estrutura rítmica e dos intervalos para a construção dos sentidos na canção. Neste artigo, no entanto, tais aspectos não serão considerados, mantendo-se o foco da análise na letra da canção.
} 
relação do sujeito com o passado. Trata-se, portanto, de um artigo de caráter descritivoqualitativo que tem como materialidade linguística a canção "Desgarrados".

\section{A construção da identidade social dos sujeitos}

De acordo com Ruben (1987), as nacionalidades são forjadas a partir de diferentes ordens de conflitos, interesses e projetos que são naturais em uma sociedade dividida em classes. Há uma espécie de pacto que une as pessoas em torno de uma ideia de identidade cultural e de valores, o que passa a compor uma hegemonia constitutiva da nacionalidade.

Trata-se, portanto, de um processo simbólico, no qual, muito mais do que o registro em um determinado território, estão em jogo elementos como o sentimento de pertença a um grupo social ao qual aparecem vinculados símbolos tais como hinos, brasões, idiomas, bandeiras e até mesmo formas de pensar e de agir.

Com o processo de globalização, era de se esperar que as identidades regionais fossem sendo gradativamente apagadas. No entanto, não foi isso que aconteceu no caso específico do estado do Rio Grande do Sul.

A memória identitária do Rio Grande do Sul é constituída por imagens mentais e objetais muito específicas, no contexto brasileiro, calcadas em personagens folclóricos e valores que se tornaram símbolo da sua história, crenças, manifestações artísticas e pretensas virtudes, as quais foram, em tese, solidificadas ao longo de muitas disputas, inclusive territoriais.

Trata-se de uma realidade que foi transposta para o nível do imaginário coletivo e que hoje é materializada por meio de discursos verbais e não verbais, reiterados por toda uma comunidade.

Como lembra Pesavento (1993, p. 383), no entanto,

há que se ter em vista que as representações do mundo social — ou as traduções imaginárias da sociedade - são também partes constituintes do real. Em outras palavras, não há uma oposição entre as condições concretas da existência (ou o "real") e as representações coletivas da mesma. Tanto o imaginário se constitui, em parte, na dependência do concreto e do racional, quanto discursos e imagens são, por sua vez, geradores de práticas sociais. Complementando, pode-se ainda afirmar que a história do imaginário se constrói a partir das relações entre a "realidade social" e o sistema de representação que ela se atribui. 
Dessa implicação se conclui que um grupo se constitui como tal quando atribui a si mesmo uma identidade e passa a projetá-la para o mundo, ao mesmo tempo em que cria uma representação do mundo em relação a si mesmo.

Pesavento (1993) destaca que não necessariamente essa identidade projetada precisa ser o reflexo do real. Por vezes, o discurso sobre o real passa a ter mais valor do que o próprio real. O imaginário social coloca-se, assim, no lugar do próprio real, marcando uma ruptura em relação à coisa representada, dado que ele - o imaginário extrapola o limite do racional, ganhando dimensões que se aproximam do sonhado, do utópico e do desejado.

Obviamente, é preciso admitir que há, nesse processo, uma manipulação da realidade em função de interesses determinados. Tem-se, então, um processo de formação da memória manipulado, controlado por interesses nem sempre explícitos. Para essa formação, entra em jogo uma seleção de discursos que privilegia alguns dados, enquanto omite outros, tidos como menos importantes ou menos dignos.

Pode-se dizer, nesse viés, que a história é sempre uma representação da realidade, e não a realidade em si, a qual só pode ser acessada por meio dos discursos sobre os fatos e, por isso mesmo, é passível de manipulação.

$\mathrm{Na}$ sequência, pretende-se analisar algumas características que marcam a formação da identidade gaúcha, em específico.

\subsection{A construção identitária do gaúcho}

Um primeiro fator que tem de se levar em conta na formação da sociedade gaúcha é que o estado do Rio Grande do Sul é limítrofe com outros países, compondo a fronteira sul do país. De acordo com Rosa (1957), há uma vontade, desde sempre, de o gaúcho ser "brasileiro", vontade que se tornou ainda mais latente em épocas de guerra. Isso acabou por associar a figura do gaúcho a uma imagem de camaradagem, de luta conjunta pelos mesmos princípios, de afronta ao perigo, ou seja, de um sujeito heroico, que associa guerra, bravura e defesa da sua identidade e do espaço geográfico em relação aos castelhanos.

Uma segunda característica da formação do ideário coletivo do gaúcho diz respeito à relação do sujeito com a terra. Historicamente ligado ao campo, o homem gaúcho alimentou uma imagem de força e, ao mesmo tempo, de nobreza - tanto é que a 
literatura gaúcha eternizou a alegoria de "centauro dos pampas"4: ser mitológico que representaria o gaúcho, na sua força e na sua nobreza, bem como no não reconhecimento de limites para o alcance das suas metas. Um destaque, nesse sentido, é a prevalência da figura masculina sobre a feminina: o mundo gaúcho é dos homens, e não das mulheres, sendo que, inclusive, o cavalo aparece referido muito mais frequentemente como companheiro do gaúcho, e não a mulher, relegada a um segundo plano. Nos relatos, é sempre a figura masculina a responsável pela tomada das vastas extensões de terra e pela apropriação dos rebanhos, colocando-se como responsável pela estância e sendo o senhor da guerra e da paz.

Ligando-se a essas duas características, está a opção política e ideológica regional (PESAVENTO, 1993): o gaúcho tem uma relação ancestral com a terra, a qual compõe a sua personalidade e de forma idealizada forja o seu caráter teoricamente libertário, democrático, sem distinções de classes ou raças. Trata-se, obviamente, de uma visão estereotipada, figurativizada, inclusive, no ato de tomar chimarrão na mesma cuia, fazer parte da mesma roda em torno da fogueira, partilhando da carne gorda no churrasco, numa situação de plena camaradagem, em que o patrão é visto como "naturalmente" superior aos peões, que aceitam a sua "inferioridade" como se fosse, também, algo natural. Assim, os conflitos são projetados como algo externo à realidade do gaúcho. Até mesmo o progresso é tomado como contrário à tradição, e, portanto, negativo à essência da sociedade gaúcha: é preciso preservar o passado a qualquer custo.

Sobre isso, aponta Pesavento (1993, p. 391):

Esse é, sem dúvida, um processo de falseamento do real e de deslocamento de sentido, não só porque a sociedade jamais pode ser estática, mas porque o modelo nunca existiu em sua integridade. A reconstrução idílica de tal sociedade nunca correspondeu às condições históricas e concretas do movimento em que os exemplos e sinais foram recolhidos, nem ao momento em que o mito é construído (...).

Tem-se, com isso, a perpetuação da valorização do latifúndio, do trabalho no campo, referente a um passado glorioso construído pelo imaginário social.

\footnotetext{
${ }^{4}$ Corporeidade mitológica - meio cavalo, meio homem - associada à imagem do gaúcho leal, honrado, valente e viril. Vários autores fazem referência à figura do centauro dos pampas, tanto na literatura quanto em artigos de cunho científico: CÉSAR, Guilhermino. História da literatura do Rio Grande do Sul. Porto Alegre: Editora Globo, 1956. LOPES NETO, João Simões. Obra Completa. Porto Alegre: Sulina, 2003; PESAVENTO, Sandra Jatahi. Gaúcho: mito e história. Letras de hoje. Porto Alegre. n. 77 (set. 1989), p. $55-63$.
} 
Por fim, um último elemento responsável pela formação desse imaginário diz respeito à articulação entre a imagem própria do sujeito e o público que o vê (PESAVENTO, 1993). Pode ocorrer, segundo a autora, uma espécie de amnésia parcial da população em geral, em que é apagado, por exemplo, o empobrecimento e a marginalização ocorridos no processo de deslocamento do interior para a cidade, mantendo-se viva na lembrança a honra pelo passado, o que atenuaria, então, o sofrimento atual. Por isso, a estratégia de endossar símbolos e crenças por parte dos indivíduos não pode ser tomada como um processo de manipulação por parte de terceiros, mas sim de uma ação voluntária com vistas a resguardar, através de uma representação mental, a sua participação social e o seu pertencimento a um mundo reconhecido e justo. O real representado, que nada mais é do que um imaginário, passa a ser mais vivo, mais colorido, mais envolvente do que o real existente. Assim, a invenção do social pode se mostrar muito mais atrativa do que a realidade.

Na sequência, passa-se a apresentar alguns conceitos básicos da semiótica de linha greimasiana, especialmente focando nos aspectos ligados à enunciação, quais sejam os ligados ao nível discursivo, elementos esses que permitirão, mais tarde, proceder à análise dos elementos isotópicos que colaboram para construir o ethos do gaúcho no texto a ser analisado.

\section{Sobre a semiótica discursiva e a enunciação na perspectiva semiótica}

A semiótica - teoria proposta por Algirdas Julien Greimas - defende que o texto possui dois planos: o de expressão - que não será aqui abordado - e o de conteúdo. É nesse último que se instaura o percurso gerativo de sentido, o qual se estrutura do simples e abstrato para o complexo e concreto, percurso esse sucintamente apresentado a seguir.

No nível das estruturas fundamentais, há uma oposição semântica a partir da qual o todo do texto é estruturado, consistindo, desse modo, no conteúdo mínimo fundamental, sendo cada termo dessa oposição determinado, no âmbito do próprio texto, como positivo ou negativo - eufórico ou disfórico. Tem-se, assim, a ideia de vida e morte, por exemplo, consistindo no ponto de partida para a geração de um dado discurso.

No nível narrativo são analisadas as relações e as disputas travadas entre sujeitos na busca por diferentes objetos-valor, assim como as transformações decorrentes desse processo, o que, segundo Barros (1997, p. 16), simula "tanto a história do homem em 
busca de valores ou à procura de sentido quanto a dos contratos e dos conflitos que marcam os relacionamentos humanos". Neste nível, busca-se a narratividade do texto, entendida esta como qualquer mudança de estado operada por sujeitos na busca por determinados objetos-valor. A semiótica concebe que uma narrativa canônica compreende quatro fases que se pressupõem mutuamente: manipulação, competência, performance e sanção. Na manipulação, um sujeito é levado a agir pelo querer-fazer ou pelo dever-fazer. A competência implica o poder-fazer e o saber-fazer, ou seja, para realizar a performance o sujeito precisa saber/poder-fazer. A performance compreende a transformação principal operada na narrativa. A sanção ocorre quando se reconhece a transformação realizada e, então, o sujeito que a operou é premiado ou castigado. É preciso dizer, ainda, que essas fases não aparecem todas explícitas num texto, elas precisam ser pressupostas pelo leitor. Um texto pode, por exemplo, relatar a apenas a transformação ocorrida, mas para que se realize uma transformação precisa haver um sujeito que queira ou deva realizá-la (manipulação) e que saiba e possa efetuá-la (competência).

Já no nível discursivo - em que se concentram os estudos deste artigo -, os valores assumidos pelos sujeitos da narrativa são "disseminados sob a forma de percursos temáticos e recebem investimentos figurativos" (BARROS, 1997, p. 68). A tematização e a figurativização consistem em procedimentos semânticos do discurso, sendo que através da reiteração de figuras e temas o sujeito da enunciação assegura a coerência narrativa e cria diferentes efeitos de sentido. As redes temáticas e figurativas que se formam por meio da recorrência de traços em determinado texto são chamadas de isotopias (GREIMAS e COURTÉS, 2008), sendo elas que garantem a linha sintagmática do texto e a sua coerência semântica.

As estruturas discursivas são da seguinte maneira definidas por Barros (1997, p. 86):

O nível das estruturas discursivas constitui o patamar mais superficial do percurso de geração do sentido de um texto, o mais próximo da manifestação textual. As estruturas discursivas, "enriquecidas" semanticamente, são mais específicas e mais complexas que as estruturas narrativas e fundamentais.

O conceito de figuras e temas interessa sobremaneira a esse trabalho, para o que se recorre, então, à conceituação apresentada por Fiorin (1997, p. 65): 
A figura é todo conteúdo de qualquer língua natural ou de qualquer sistema de representação que tem um correspondente perceptível no mundo natural. [...] Tema é um investimento semântico, de natureza puramente conceptual, que não remete ao mundo natural.

Tem-se, assim, as figuras como elementos que simulam o mundo, enquanto que os temas organizam, categorizam, ordenam os elementos do mundo natural.

Atrelados ao nível discursivo, surgem os estudos enunciativos na perspectiva semiótica, nos quais se analisam as escolhas enunciativas do enunciador - em função de um certo enunciatário - e os efeitos de sentido que essas escolhas projetam no texto. Por isso, em semiótica, considera-se que enunciador e enunciatário constituem, ambos, o sujeito da enunciação.

Dentre os vários mecanismos enunciativos que marcam as escolhas do enunciador, as categorias de pessoa, tempo e espaço são as mais estudadas. Porém, como se verá na análise, há muitos outros elementos que, instaurados no texto, produzem efeitos de sentido e permitem construir imagens discursivas do sujeito (BARROS, 2012), fazendo com que a enunciação funcione como um jogo em que o sujeito da enunciação constrói-se enquanto ator da enunciação, crivado por crenças e valores de um determinado grupo, que faz certas escolhas enunciativas para convencer o seu enunciatário, manipulando-o. Tal manipulação, dentro do jogo persuasivo, portanto, só ocorre mediante o fazer interpretativo do destinatário, configurando-se como um fenômeno ao mesmo tempo cultural e discursivo. Há, assim, uma interação entre enunciador e enunciatário através de diferentes efeitos de sentido no enunciado.

A instalação das categorias de pessoa, tempo e espaço no enunciado se dá por meio do mecanismo chamado debreagem. Como são três as categorias da enunciação, também são três os tipos de debreagens: actancial (de pessoa), temporal e espacial. As debreagens podem ser enuncivas - quando se projeta no texto a terceira pessoa "ele", no tempo do "então" e no espaço do "lá", ou enunciativas - quando ocorre a projeção em primeira pessoa, no tempo do "agora" e no espaço do "aqui" (FIORIN, 2003). Enquanto no primeiro caso criam-se no enunciado efeitos de objetividade e de distanciamento entre enunciador e enunciatário, no segundo caso projetam-se no texto efeitos de subjetividade e de aproximação, através do emprego do eu-tu/ aqui/agora.

É na instância discursiva que repousam os elementos responsáveis pelo possível estabelecimento do ethos discursivo, elemento que se passa a detalhar em seguida. 


\section{Imagens de sujeito construídas no/pelo discurso}

Nos estudos sobre o ethos, o que está em jogo é a forma como o locutor age sobre o seu parceiro na troca verbal, ou seja, a forma como os interlocutores agem uns sobre os outros por meio de uma rede de influências mútuas. É nesse processo de construção da significação, da imagem de si e do outro, que se manifesta a natureza profundamente interacional da linguagem. O interlocutor quer fazer com que o seu interlocutário tenha uma determinada imagem a seu respeito, de tal maneira que seja essa a imagem de certa forma imposta ao outro. Assim é que, no mundo cotidiano das interações, os sujeitos lançam mão de certos recursos linguísticos com vistas a confirmar, por exemplo, o seu conhecimento sobre determinado tema, ou a sua propriedade para emitir uma opinião a respeito de alguém, ou a sua experiência em certa área para sugerir um comportamento em específico. Em outros termos, trata-se de garantir que na interação conversacional as relações interpessoais sejam vistas como legítimas, e, portanto, os seus interlocutores sejam reconhecidos como tal. Não há dúvidas, nesse sentido, de que se trata de papéis já ritualizados socialmente que devem ser resgatados ou mantidos.

A noção de ethos que figura hoje em diversas correntes da análise do discurso tem origem nos estudos antigos sobre a retórica, mais especificamente na Retórica de Aristóteles, em que se buscava compreender como o discurso do orador alcançava o êxito na persuasão do enunciatário. A tríade implicada num ato de comunicação era composta, então, pelo ethos, o logos e o pathos. Grosso modo, o ethos diz respeito à imagem do locutor produzida pelo discurso; o logos é o discurso em si, diz respeito às escolhas nele projetadas; e o pathos diz respeito à imagem de enunciatário implicada no discurso, relacionada ao estado de espírito, ou às "paixões" deste.

Embora tenha sua origem nos estudos sobre o discurso argumentativo, o ethos não se restringe a essa modalidade discursiva. Segundo Amossy (2005, p.24), Dominique Maingueneau foi responsável por mostrar que o ethos aparece não apenas em discursos argumentativos, mas em qualquer troca verbal, incluindo tanto as interações faladas quanto as escritas. Para Maingueneau (2008), o ethos está relacionado a uma maneira de dizer que remete a uma maneira de ser atrelada a uma cena enunciativa que valida o que é dito e como é dito. Em seus estudos, o autor problematiza e amplia a noção de ethos concebida a partir da Retórica de Aristóteles, conservando dela preceitos básicos: 
- o ethos é uma noção discursiva, ele se constitui por meio do discurso, não é uma imagem do locutor exterior à fala;

- o ethos é fundamentalmente um processo interativo de influência sobre o outro;

- o ethos é uma noção fundamentalmente híbrida (sociodiscursiva), um comportamento socialmente avaliado, que não pode ser apreendido fora de uma situação de comunicação precisa, ela própria integrada a uma conjuntura sócio-histórica determinada. (MAINGUENEAU, 2008, p. 63, grifos do autor)

Assim, em todas as situações, nas diferentes linhas teóricas que foram surgindo com o passar do tempo e às quais foram sendo acrescidos fatores de análise, destacados alguns pontos e suprimidos outros, trata-se de analisar a fala como uma ação que tem como meta influenciar o outro, o interlocutor, em outras palavras, alcançar êxito com um enunciado. $\mathrm{O}$ intuito final de todo e qualquer ato de comunicação não é informar, mas sim persuadir o outro a aceitar o que está sendo comunicado. Como refere Fiorin (2016, p. 55), “comunicar é agir sobre o outro e, por conseguinte, não é só levá-lo a receber e a compreender mensagens, mas é fazê-lo aceitar o que é transmitido, crer naquilo que se diz, fazer aquilo que se propõe".

Nesse jogo de persuasão, entram em cena "imagens" do enunciador e do enunciatário. Ou seja, o enunciador, ao produzir um enunciado, tem em mente uma imagem de enunciatário e, em função dessa imagem, projeta no texto determinadas escolhas enunciativas (lexicais, semânticas, sintáticas etc.) e não outras, assim como confere ao texto um certo "tom". Afinal, é preciso estar constantemente adaptando o enunciado ao enunciatário.

Como o texto projeta as escolhas enunciativas do enunciador voltadas à adesão de um determinado enunciatário (ou de um público determinado), é possível depreender, pelas marcas ali projetadas, uma imagem discursiva do enunciador (ethos) e do enunciatário (pathos). O ethos, então, não seria uma imagem de "sujeito real”, "de carne e osso", mas sim uma espécie de imagem do caráter do enunciador possível de depreender a partir da análise dos discursos por ele proferidos. É comum, por exemplo, “atribuir a Machado de Assis um ethos de cinismo, ceticismo e ironia pelo que se depreende de suas obras. Não importa se o autor real, o homem Machado de Assis, tinha ou não tais características. Importa que é essa a 'imagem de autor' que transparece em suas obras" (CRESTANI, 2010, p. 231-232). Essa imagem é o ethos.

O ethos discursivo, portanto, explicita-se "nas marcas da enunciação deixadas no enunciado. [...] Trata-se de apreender um sujeito construído pelo discurso" (FIORIN, 
2008, p. 139). Em termos simplificados, os estudos centrados no ethos procuram perceber o que as marcas enunciativas/discursivas projetadas no texto permitem dizer sobre o enunciador, que imagens constroem sobre ele. É, pois, na materialidade discursiva da totalidade que estão as recorrências dos elementos composicionais que compõem o ethos: a escolha do assunto, a construção dos personagens, o nível de linguagem usado, as isotopias estabelecidas (FIORIN, 2017).

\section{Análise da canção "Desgarrados": o espaço físico e o gaúcho que olha para o passado}

Passa-se, nesta secção, à análise da canção "Desgarrados”, composta por Mário Barbará e Sérgio Napp, à luz dos conceitos anteriormente apresentados. Assim, inicialmente, é preciso indicar, mesmo que de maneira sumária, alguns aspectos sóciohistóricos pertinentes à análise que será realizada.

A canção é lançada em pleno período da ditadura militar brasileira, tendo sido vencedora da Califórnia da Canção Nativa de 1981, em Uruguaiana, evento artístico musical do Rio Grande do Sul que ocorre desde 1971.

Politicamente, os anos de 1970 foram marcados pelo apogeu do golpe militar no Brasil e pela quantidade de propaganda oficial, lançada inclusive em slogans e em músicas - quem não lembra da canção Eu te amo meu Brasil, eu te amo / Meu coração é verde, amarelo, branco, azul anil / Eu te amo meu Brasil, eu te amo, cantada pelo grupo Os Incríveis? No entanto, apesar da intensa campanha de censura aos meios de comunicação e às artes, a resistência à repressão surgiu em diversos meios, inclusive no musical.

No início dos anos 80, época em que foi lançada a canção "Desgarrados" - o país ainda vivia a ditadura militar, mas o então presidente Ernesto Geisel, militar, já acenava para a criação de condições de uma abertura política e do fim do militarismo (REGO e MARQUES, 2005).

No Rio Grande do Sul, arrefecia o significativo processo de deslocamento campocidade, em busca de melhores condições de vida, ocorrido ao longo dos anos de 1970. Mas eram evidentes os problemas oriundos dessa grande urbanização sem qualquer planejamento (ALMEIDA, 1990), e os reflexos disso já se faziam sentir: subemprego, 
falta de condições dignas de moradia, aumento do índice de violência urbana, dentre outros.

Nesse contexto, "Desgarrados" é lançada e se torna uma espécie de hino extraoficial dos gaúchos:

Desgarrados

Eles se encontram no cais do porto, pelas calçadas

Mário Barbará e Sérgio Napp

Fazem biscates pelos mercados, pelas esquinas

Carregam lixo, vendem revistas, juntam baganas

E são pingentes nas avenidas da capital.

Eles se encontram pelos botecos entre os cortiços

E pra esquecerem, contam bravatas, velhas histórias

Então são tragos, muitos estragos por toda a noite

Olhos abertos o longe é perto, o que vale é o sonho.

Sopram ventos desgarrados, (refrão)

Carregados de saudade,

Viram copos, viram mundo,

Mas o que foi nunca mais será

Cevavam mate, sorriso franco, palheiro aceso

Viravam brasas, contavam casos polindo esporas

Geada fria, café bem quente, muito alvoroço

Arreios firmes e nos pescoços lenços vermelhos.

Jogo do osso, canário de espera e pão de forno

O milho assado, a carne gorda, a cancha reta

Faziam planos e nem sabiam que eram felizes

Olhos abertos o longe é perto, o que vale é o sonho.

A canção "Desgarrados" é bastante representativa de um conjunto de bens materiais e simbólicos do gaúcho. Deve-se ter em mente, porém, que as manifestações literárias - dentre as quais está o gênero canção - não têm compromisso com a realidade, muito embora determinadas obras literárias tenham formado representações coletivas do passado tanto ou mais eficientes que a narrativa historiográfica ou simplesmente diferentes dela (CHARTIER, 2009). Na canção em foco, ficção e realidade se misturam.

O texto não segue uma organização cronológica, apresentando, na primeira estrofe, a situação atual dos personagens, enquanto que a segunda estrofe apresenta o contexto anterior àquele. Seguindo, para fins de análise, uma organização temporal, podese observar, na segunda estrofe, os sujeitos - trabalhadores do campo - em conjunção com os objetos-valor alegria, felicidade, bem-estar, companheirismo, autonomia, existentes no ambiente rural. No entanto, os mesmos sujeitos sentem-se, simultaneamente, em disjunção com o objeto-valor bem-estar, apesar de estarem, efetivamente, em conjunção 
com ele, buscando-o, então, no ambiente urbano. Dessa forma, é possível dizer que o texto aborda a oposição campo versus cidade.

O que subjaz a essa oposição, porém, é a idealização presente em ambos os espaços físicos: tanto é ficcionalizado o ambiente rural, em que os sujeitos estavam antes da mudança, quanto o espaço urbano que os sujeitos esperam encontrar. Assim, os sujeitos, dada a sua situação no campo e a consequente situação na área urbana, desenvolvem um programa narrativo de privação ${ }^{5}$ ao urbanizarem-se, tendo em vista a falsa imagem de conforto e comodidade representada pelo grande centro urbano. A manipulação dos sujeitos ocorre por meio, paralelamente, da tentação e da sedução, não ficando evidentes, no entanto, a fase da competência nem a da performance. O texto somente faz menção à sanção sofrida pelos sujeitos: a pobreza e a degradação de valores. Em seguida, os sujeitos são manipulados pelo querer-fazer - o desejo de retornar ao ambiente rural. No entanto, ocorre, neste segundo programa, que os sujeitos não são modalizados pelo poder ou pelo saber fazer, não se realizando, portanto, a performance. Estabelecem, assim, com os objetos-valor felicidade, abundância, honestidade, um estado disjuntivo.

O título da canção - "Desgarrados" - vem confirmar a ideia de que o texto aborda a questão do êxodo rural, apontando para os prejuízos sociais e morais advindos do deslocamento de pessoas do interior do estado do Rio Grande do Sul para a capital, Porto Alegre.

A análise revela uma organização complexa: os desgarrados saíram do passado rural idealizado para o presente da cidade, antes idealizado e, agora, decepcionante. Isso permite aventar a hipótese de que esses sujeitos não estavam satisfeitos com a vida no campo e imaginavam ser melhor na cidade, o que se mostrou, depois, não só pior do que esperavam, mas também pior do que era a vida no campo, como a canção mesma explicita: faziam planos e nem sabiam que eram felizes. Corrobora-se a tendência de edulcorar o passado como uma época de ouro, de um tempo que já foi, de fartura e felicidade que nunca mais será.

\footnotetext{
${ }^{5}$ Um programa narrativo (PN) de aquisição configura-se nas situações em que o sujeito passa de uma situação inicial de disjunção com o objeto-valor para uma situação final de conjunção com este. No caso contrário, em que o sujeito passa de uma situação de conjunção para uma de disjunção, configura-se um PN de privação.
} 
No nível discursivo, foco deste trabalho, tem-se a cadeia isotópica do rural, composta pelos elementos figurativos mate, palheiro, casos, café quente, alvoroço, lenço vermelho, milho assado, dentre outros. Todas essas figuras, presentes na segunda estrofe e representativas da vida no campo, remetem a um estilo de vida tranquilo, repleto de amizade, convívio social e fartura. Tem-se, aí, um campo semântico que recupera o passado rural do estado do Rio Grande do Sul e a figura do gaúcho enquanto indivíduo emblemático, de bem com a vida e absolutamente à vontade no ambiente rural, apesar da dificuldade natural ao meio - geada fria - e a vida simples - virar brasas, milho assado. Trata-se, é preciso deixar claro, de uma visão idealizada deste espaço, o qual não condiz, como posteriormente se verá, com a realidade histórica.

Já a primeira estrofe figurativiza a vida no ambiente urbano por meio da isotopia formada por biscates, lixo, botecos, cortiços, bravatas, estragos. Tais figuras mostram um outro tempo vivido pelos sujeitos - o agora, não mais no campo, mas sim na cidade. É no ambiente urbano que os sujeitos perdem seus valores, é nele que surgem os vícios e que os sujeitos passam a viver em condições pouco dignas - carregam lixo, juntam baganas, moram em cortiços. Também chama a atenção o fato de que não há, nessa estrofe que trata da urbanidade, nenhuma referência à comida: partindo-se do pressuposto que o silêncio em um texto também é significativo, pode-se inferir, com isso, a privação pela qual os sujeitos passam, inclusive de alimento.

Na perspectiva histórica, há a denúncia de uma situação social típica dos anos anteriores ao lançamento da canção: o êxodo rural que havia marcado os anos de 1970 e os seus reflexos - subemprego, falta de condições dignas (ALMEIDA, 1990).

Tem-se, assim, a literatura, nesse caso, ocupando o papel de um arquivo no qual são depositadas as imagens representativas de um determinado período: o gaúcho que sai do campo e vai para a cidade e, com isso, perde a sua identidade. Há, obviamente, uma imagem hipertrófica a respeito desse gaúcho interiorano: como refere Pesavento (1993), o gaúcho tem uma relação ancestral com a terra, a qual forja, de maneira idealizada, o seu caráter libertário, democrático, camarada e bonachão, que aceita a sua situação de respeito pelo "patrão" sem, no entanto, se sentir submisso a ele ou humilhado na sua condição. É, portanto, o resgate de um passado glorioso somente existente no imaginário social.

Também é interessante notar que o enunciador refere, ao longo do texto, o desejo de retorno a um espaço - o espaço do campo. E o faz com uma espécie de nostalgia, carregada de sentimento, tal qual a acepção inicial que se tinha de nostalgia, tomada como 
uma doença da memória (NATALI, 2006) ${ }^{6}$ - há um sentimento de dor, de perda envolvido - o que foi, nunca mais será. Reconhece-se, no refrão, a impossibilidade de voltar, o que não impede o desejo. O retorno mais desejado não é exatamente o espacial, constituindo o que atualmente se denominaria "êxodo urbano": é o retorno no tempo, ao tempo em que, estando no campo, o sujeito tinha acesso a condições dignas de vida, à fartura - carne gorda, à camaradagem - sorriso franco, ao controle da sua própria vida arreios firmes, fazer planos. É, pois, uma invenção e uma cristalização de uma forma do passado que não necessariamente corresponde à realidade.

Oliven (1998, p. 78), em artigo em que analisa o renascimento do gauchismo, especialmente considerando os festivais de música nativista, destaca que para os "atores" do tradicionalismo ${ }^{7}$ :

manter a distinção entre o Rio Grande do Sul e o resto do Brasil seria uma forma de preservar a identidade cultural do estado. Por isso, um elemento recorrente no discurso tradicionalista é a referência à ameaça que estaria pairando sobre a integridade gaúcha.

Na situação narrativizada na canção, a "ameaça" seria a urbanização, que levaria à perda do caráter rural do gaúcho. Isso é interessante se for considerado o fato de que o Estado hoje, e já em 1981, época em que a música foi lançada, era predominantemente urbano - muito embora, como já dito anteriormente, o êxodo rural tenha sido muito grande nos anos de 1970. De qualquer forma, o que transparece na letra é que ceder à urbanização é enfraquecer o poder regional, aceitando a homogeneização e a padronização de hábitos.

Embora se projete na letra da canção a debreagem actancial em terceira pessoa (eles), criando efeito de sentido de distanciamento entre narrador e fato narrado - aquele não se inclui neste - as demais escolhas enunciativas projetam efeitos de aproximação. A rede figurativa do texto cria uma espécie de identificação dos sujeitos rio-grandenses com os atores do enunciado e os fatos narrados, ancorados $^{8}$ que estão em espaços conhecidos

\footnotetext{
${ }^{6}$ De acordo com Natali (2006), a palavra nostalgia foi criada pelo médico suíço Johannes Hofer, em 1688. Origina-se do grego nostos (voltar para casa) e algos (sofrimento), significando a impossibilidade de saciar o desejo de voltar para casa.

${ }^{7}$ Não é feita, nesse trabalho, distinção entre tradicionalismo e nativismo. Sobre isso, sugere-se consultar Oliven (1998), conforme bibliografia.

${ }^{8}$ De acordo com Barros (1997, p. 84), a ancoragem é "o procedimento semântico do discurso por meio de que o sujeito da enunciação 'concretiza' os atores, os espaços e os tempos do discurso, atando-os a pessoas, lugares e datas que seu destinatário reconhece como 'reais' ou 'existentes' e produzindo, assim, o efeito de sentido de realidade ou de referente".
} 
da realidade gaúcha, tanto urbana quanto rural. Para a ancoragem no eixo rural, tem-se, como já referido, a rede figurativa formada por mate, virar brasas, contar caos, polir esporas, geada fria, arreios firmes, lenços vermelhos, pão de forno, cancha reta, carne gorda, milho assado. Para a ancoragem no eixo urbano, há a referência a elementos figurativos como calçadas, mercados, esquinas, botecos, cortiços, típicos de uma cidade grande, sendo que os elementos cais do porto e a expressão avenidas da capital localizam espacialmente a cena na cidade de Porto Alegre.

Uma análise complementar, bem mais ampla é que a canção, além de retratar uma realidade típica da cultura gaúcha de um certo período, reflete a própria condição humana: estando em uma dada situação, o indivíduo deseja alcançar outra, distante, projetando nela a sua felicidade e desprezando a situação vivida - faziam planos e nem sabiam que eram felizes. No entanto, alcançando essa outra situação, descobrem que ela não é o que esperavam, projetando novamente sua felicidade em outro espaço, em outro tempo. É a saga humana, de busca eterna da felicidade não no aqui/agora, mas no lálentão. No nível fundamental do texto, pode-se estabelecer a dicotomia realidade/ilusão, sendo que os indivíduos tanto romantizam o seu passado quanto idealizam o que está por vir, sem que a idealização efetivamente se concretize.

Todas essas considerações permitem, imagina-se, traçar um ethos do enunciador, aqui tomado como representante da identidade gaúcha. Tomamos, portanto, o modo de enunciação, especialmente considerando a análise de nível discursivo da semiótica greimasiana, como referência para o estabelecimento do ethos. Mesmo em "Desgarrados", em que há uma pseudo objetividade/neutralidade, marcada pelo discurso em terceira pessoa - eles, não há o apagamento do sujeito, mantendo-se muito forte a subjetividade na narrativa.

Fica evidente no texto, considerado na sua totalidade, um ethos nostálgico e arrependido: ao mesmo tempo em que o enunciador quer retornar ao espaço do campo e ao tempo de outrora, em que havia felicidade, comida, dignidade, ele mesmo admite a impossibilidade do retorno, no refrão - Sopram ventos desgarrados/ Carregados de saudades /Viram copos, viram mundos/Mas o que foi nunca mais será. Aquele que saiu do campo é um desgarrado, perdeu-se da sua origem campeira, da qual tem saudades. Seu mundo se modificou - viram mundos - o campo se transformou em cidade, e a bebida parece ser o único conforto para tolerar a dureza da vida atual - viram copos. No entanto, o que foi nunca mais será - não se banha duas vezes no mesmo rio: como dizia o filósofo 
pré-socrático Heráclito de Éfeso, pois na segunda vez o rio já não é o mesmo, tampouco aquele que se banha. Da mesma forma, não é possível voltar atrás num modelo de vida desejado depois de conhecer o outro lado: a cidade e a sua realidade cruel deixa marcas profundas e irreversíveis no sujeito. O ethos nostálgico é reforçado na saudade do passado repetida no refrão, embora reconhecida, como já dito, a impossibilidade de voltar a tê-lo.

Trata-se, pois, de uma espécie de exceção do gaúcho em relação ao restante do país: ser brasileiro - leia-se urbanizado - não é significativo se não houver a preservação da marca do gauchismo - leia-se ruralizado. O ethos gaúcho está, dessa forma, diretamente relacionado à formação de uma ideologia regionalista e, segundo muitos, extremamente bairrista. Gaúcho de fato parece ser apenas aquele que está ligado aos valores campeiros, e não o gaúcho que se urbaniza. A urbanização, assim, marca a degradação do gaúcho, o que explicaria o desejo de se ficar preso ao passado telúrico e idealizado.

Para que não haja uma interpretação equivocada, é preciso admitir como natural e salutar que os povos nutram um amor-próprio. O problema é que isso não pode se tornar de tal forma alienante que negue os rumos de uma sociedade globalizada que se modifica constantemente no contato com outras culturas e com outras formas de viver, como parece fazer o texto "Desgarrados".

Há, nele, uma fratura, uma ruptura entre o passado e o presente, e emerge o tempo todo o desejo de retorno a esse passado idealizado através da nostalgia. O enunciador constrói uma imagem hipertrófica para o gaúcho que vive na lida do campo - resiste à geada fria, come carne gorda, tem a vida sob o seu controle. E essa imagem hipertrófica, irreal, é absolutamente conflituosa em relação à imagem que ele efetivamente passa a ter na cidade, onde passa a ser apenas um a mais. É isso que o ethos do enunciador revela: o desejo de voltar a um tempo e a um espaço em que fosse possível ser dono do seu próprio destino.

O passado é, portanto, neste caso, uma invenção de hoje. E nesse jogo, há um traço nostálgico - o retorno não é possível, mas pelo menos se guardam as lembranças, ou, como diria o poeta brasileiro Manoel de Barros (1916-2014), guardam-se as memórias inventadas. 


\section{Considerações finais}

Muito embora se tenha analisado apenas uma canção neste artigo, permitimo-nos afirmar, considerando que tantas outras canções seguem esse mesmo padrão, que a nostalgia é um traço muito comum na cultura gaúcha, sendo "Desgarrados" um texto prototípico nesse sentido.

Segundo Vecchi (2017), há casos em que a história não dá conta de retratar algumas realidades, algumas vezes por contingências políticas, como no período da ditadura militar, por exemplo, e aí a literatura preenche tais lacunas. Na situação analisada neste artigo, tem-se a literatura contando uma história idealizada a respeito dos espaços rurais do Rio Grande do Sul e da "lida do campo", em que todas as agruras oriundas das privações, do frio, da distância em relação aos recursos médicos ou tecnológicos são apagadas. Os espaços e tempos que não o aqui/agora representam a ilusão de um futuro melhor, que, no entanto, não se concretizam jamais - deles sobrevêm a frustração e o desejo de mudança.

De acordo com Vecchi (2017), o relato literário pode, em muitos casos, constituirse como uma espécie de falsificação da história. É exatamente essa a situação em que se enquadra "Desgarrados". E não há nisso nenhum problema. Mas é preciso admitir, como se defende neste trabalho, que assim como esta canção tantas outras do cancioneiro gauchesco recriam uma história romantizada que jamais ocorreu, num comportamento nostálgico que marca o ethos gaúcho.

Trata-se, sem dúvidas, de fragmentos de uma história imaginada, irreal, de idealização da vida no campo representada no texto, em oposição ao retrato de uma vida urbana permeada de dificuldades, vícios, pobreza, solidão. É uma cena urbana de privações que se configurou para muitos sujeitos que abandonaram o campo para viver na cidade. Acima de tudo, é a busca por um lugar social idealizado, ficcionalizado: o sonho de uma vida melhor.

As isotopias figurativas apresentadas na canção remetem a um contexto rural harmônico, saudável, onde impera/imperava a felicidade e a honestidade. As isotopias relativas ao contexto urbano remetem à solidão, à decadência, à perda de valores, à morte dos princípios. Sendo, no entanto, a urbanização um processo irrefreável na atualidade, estaria, então, o gaúcho "deixando de ser gaúcho"? Teria o gaúcho de voltar à vida junto à terra para ser de fato considerado fiel às suas origens? Que volta seria essa, se, afinal, 
muitas gerações já se formaram em contextos urbanos sem jamais terem tido vínculo com o interior?

Enfim, evidencia-se, com as discussões feitas, que o ethos nostálgico do gaúcho, presente em manifestações culturais constantemente evocadas pelo "espírito gaúcho", faz com que ele esteja permanentemente a olhar para o passado, lamentando não poder retomá-lo. O eu gaúcho, nesse contexto, não se reinventa: está sempre com um olhar para o que já foi, numa perspectiva, portanto, reacionária, sem admitir, como diz a canção, que o que foi nunca mais será.

\section{Referências}

ALMEIDA, P. F. C. (Coord.). A economia gaúcha e os anos 80: uma trajetória regional no contexto da crise brasileira. Porto Alegre: Fundação de Economia e Estatística, 1990.

AMOSSY, R. Da noção retórica de Ethos à análise do discurso. In: AMOSSY, R. (Org.) Imagens de si no discurso. São Paulo: Contexto, 2005, p. 9-28.

BARBARÁ, Mário; NAPP, Sérgio. Desgarrados. XI Califórnia da Canção Nativa de Uruguaiana. Gravadora K-Tel, 1981. Disponível em: https://immub.org/album/xicalifornia-da-cancao-nativa-do-rio-grande-do-sul. Acesso em: 12 mar. 2019.

BARROS, D. L. P. Teoria semiótica do texto. São Paulo: Editora Ática, 1997.

BARROS, D. L. P. Algumas reflexões semióticas sobre a enunciação. In: DI FANTI, M. G. e BARBISAN, L. Enunciação e discurso. São Paulo: Contexto 2012, p. 25-49.

CÉSAR, Guilhermino. História da literatura do Rio Grande do Sul. Porto Alegre:

Editora Globo, 1956.

CHARTIER, R. A história ou a leitura do tempo. Tradução Cristina Antunes. Belo Horizonte: Autêntica Editora, 2009.

CRESTANI, L. M. A oralidade como estratégia enunciativa no jornal on-line. Tese de Doutorado em Letras. Universidade Presbiteriana Mackenzie, São Paulo, 2010. Acesso em: 23 nov 2017.

FIORIN, J. L. Elementos de análise do discurso. 9.ed. São Paulo: Contexto, 1997.

FIORIN, J. L. Pragmática. In: FIORIN, J. L. (Org.). Introdução à linguística: princípios de análise. 4. ed. São Paulo: Contexto, 2003. v. 2, p. 161-185.

FIORIN, J. L. Em busca do sentido: estudos discursivos. São Paulo: Contexto, 2008.

FIORIN, J. L. As relações entre enunciador e enunciatário. In: TOLDO, C.; STURM, L. (Org.) Enunciação e produção de sentidos: o tex to em questão - uma homenagem ao Prof. José Gaston Hilgert. Campinas: Pontes, 2016. p.51-68.

FIORIN, J. L. Argumentação. São Paulo: Contexto, 2017. 
GREIMAS, A. J. \& COURTÉS, J. Dicionário de Semiótica. São Paulo: Contexto, 2008. LOPES NETO, João Simões. Obra completa. Porto Alegre: Sulina, 2003.

MAINGUENEAU, D. Ethos, cenografia, incorporação. In: AMOSSY, R. Imagens de si no discurso - a construção do ethos. Tradução Dison Ferreira da Cruz, Fabiana Komesu, Sírio Possenti. São Paulo: Contexto, 2005, p. 69 - 92.

MAINGUENEAU, D. Problemas de ethos. In: POSSENTI, S.; SOUZA-E-SILVA, M.C. P. (Orgs.). Cenas da enunciação. São Paulo: Parábola, 2008. p. 55-73.

NATALI, M. P. A política da nostalgia: um estudo das formas do passado. São Paulo: Nankin Editorial, 2006.

OLIVEN, R. O renascimento do gauchismo. 1998, pp. 77-80. Disponível em: http://www.ufrgs.br/difusaocultural/nosoutrosgauchos/assets/encontros/arquivo/o_r enascimento_do_gauchismo_i_nos_os_gauchos.pdf. Acesso em: 20 mar. 2018.

PESAVENTO, S. J. Gaúcho: mito e história. Letras de hoje. Porto Alegre. N. 77 (set. 1989), p. 55-63.

PESAVENTO, S. J. A invenção da sociedade gaúcha. Ensaios FEE, Porto Alegre, (14) 2, p. 383- 396, 1993.

REGO, J. M.; MARQUES, R. M. (Orgs.). Economia brasileira. São Paulo: Editora Saraiva, 2005.

ROSA, O. Formação do Rio Grande: fundamentos da cultura rio-grandense. Porto Alegre: UFRGS, 1957.

RUBEN, G.R. O que é nacionalismo. São Paulo: Brasiliense. 1987.

VECCHI, R. Curso ministrado durante o Seminário Internacional de Pesquisa em Leitura, Literatura e Linguagens: novas topografias. Passo Fundo, UPF, out. 2017. 


\section{Para citar essa obra:}

CAYSER, Elisane Regina e CRESTANI, Luciana Maria. A ficcionalização dos espaços urbano e rural e a construção do ethos gaúcho na canção "Desgarrados. In: RUA [online]. Volume 25, número 2 - p. 469-488- e-ISSN 2179-9911 - Novembro/2019. Consultada no Portal Labeurb - Revista do Laboratório de Estudos Urbanos do Núcleo de Desenvolvimento da Criatividade. http://www.labeurb.unicamp.br/rua/

Capa: Cais de Mauá. Disponível em: https://gauchazh.clicrbs.com.br/porto-alegre/noticia/2019 /07/veja-a-transformacao-de-cinco-cenarios-de-cartoes-postais-de-porto-alegre-cjxp5g37i03r 301pkczdh6bm7.html

\section{Laboratório de Estudos Urbanos - LABEURB}

Núcleo de Desenvolvimento da Criatividade - NUDECRI

Universidade Estadual de Campinas - UNICAMP

http://www.labeurb.unicamp.br/

Endereço:

LABEURB - LABORATÓRIO DE ESTUDOS URBANOS

UNICAMP/COCEN / NUDECRI

CAIXA POSTAL 6166

Campinas/SP - Brasil

CEP 13083-892

Fone/ Fax: (19) 3521-7900

Contato: http://www.labeurb.unicamp.br/contato 